\title{
Assessment of the SWAT Model and the Parameters Affecting the Flow Simulation in the Watershed of Oued Laou (Northern Morocco)
}

\author{
Mourad Aqnouy ${ }^{1}$, Jamal Eddine Stitou El Messari ${ }^{1}$, Hilal Ismail ${ }^{1}$, \\ Abdelmounim Bouadila², Jesús Gabriel Moreno Navarro³, \\ Bounab Loubna ${ }^{4}$, Mohammed Reda Aoulad Mansour ${ }^{5}$
}

1 University Abdelmalek Essaadi, Faculty of Sciences Tétouan, Mhannecch II B P 212193002 Tétouan, Morocco

2 Laboratory of Georesources and Environment, USMBA, Faculty of Sciences and Techniques, Fez 30000, Morocco

3 University of Seville, Geography Regional Analysis and Physical Geoprahy Andalusian Geographic Studies, Seville, Spain

4 University Abdelmalek Essaadi, National School of Applied Sciences, Mhannecch II Tétouan, Morocco

${ }^{5}$ Department of Water Quality, Hydrological Basin Agency of Loukkos, Tetouan, Morocco

* Corresponding author's e-mail: maqnouy@uae.ac.ma

\begin{abstract}
This study evaluated the Soil and Water Assessment Tool (SWAT) model performance for modeling the portioning of rainfall in the Laou watershed (area: $940 \mathrm{~km}^{2}$ ) that extended over two different climatic settings in Morocco, (the Mediterranean sub-humid and the semi-arid). This research also investigated the significant parameters that affect the stream flow simulation. SWAT model was constructed during the period from 2004 to 2011. The modeled stream flow data was manually calibrated using flow gauges daily from 2004 to 2008 and validated for the volumetric flows from 2009 to 2011 . SWAT model results indicate that $60 \%$ of the stream is provided by the base flow. The sensitivity analysis showed that out of 28 parameters, only 6 revealed meaningful effects on the flow simulation (CN2, ESCO, SOL_AWC, ALPHA_BF, CH_N2, CH_k2) and have the most significant influence. The model proved to be very sensitive to the base flow. Furthermore our outcome indicates that SWAT can successfully replicate the daily stream flows in Laou watershed with Nash-Sutcliffe (NSE) coefficients in the range of 0.76-0.84, R2 of 0.74-0.82, RSR of 0.52-0.41 and PBIS of 12.24-8.93 respectively. In addition SWAT was found to be suitable for both climatic regions in Laou watershed. These results reinforced the multi-functionality and reliability of
\end{abstract}

SWAT as a hydrological model and a relevant tool for water resources management and controls.

Keywords: SWAT, Flow, Laou watershed, sub-humid, semi-arid, Base flow.

\section{INTRODUCTION}

Hydrological modeling provides the first solution for understanding the way that rivers act in the watershed, an indispensable component of water resources research and management as well as the model's ability to numerically simulate natural systems have progressed enormously over the last decade. For this reason, researchers across the world use several types of hydrological model to simplify the complex rainfall-runoff reactions in watersheds; Agricultural Nonpoint Source (AGNPS) [Borah et Bera, 2003], Hydrological Simulation Program-Fortran (HSPF) [Skahill, 2004], European hydrological system (MIKE SHE) [Golmohammadi, Prasher, Madani and Rudra, 2014a] Rural Engineering model with 4 parameters Daily (GR4J), Hydrological Model (HyMod) [Quan, Teng, Sun, Cheng et Zhang, 2015] [Leach, Kornelsen et Coulibaly, 2018], the Hydrologic Modeling System (HEC HMS) 
[Halwatura, Najim 2013 and Aqnouy et al. 2018] and the Soil and Water Assessment Tool (SWAT) [Khatun, 2018], many of these hydrological models have been tested and are being developed.

Topics such as which model could provide more consistent results with the observed data have recently been the main focus of several researchers. Choosing the most appropriate model for simulating the hydrological flows in a particular watershed and the specific climate was consistently a major part of the global modeling process. For example, the SWAT model has been more efficient than other models. [Wang et al., 2016][Sith and Nadaoka, 2017][Polanco, Fleifle, Ludwig and Disse, 2017]. SWAT is a well-developed tool for analysing the effects of water resource practices in the most challenging watersheds.

Researchers used the SWAT model for hydrological modeling and water resource practices in diverse climate and terrain features. [Panhalkar, 2014][Costa et al., 2015][Tuppad, Mankin, Lee, Srinivasan and Arnold, 2011][Haron, Khalid, Ali, Faiza and Rahman, 2016]. The SWAT model simulates various water functions such as filtration, evapotranspiration, runoff water production, underground recharge, other processes such as watershed growth, vegetation and crops, nitrate and phosphorus progress, and surface waters. [Jha, 2011][Ang and Oeurng, 2017][Khatun, 2018][Xuan,2018]. The SWAT model provides complete information on the hydrologic behavior of a given watershed.

Hydrologic watershed models are now essential to the successful planification of water resources, this role will be strengthened in the later years, prompting scientists and managers to invest in this field [Jha, 2011][Haberlandt, 2010]. The main objectives of this work are: i) evaluate the potential and constraints of the SWAT to model the components of the Laou catchment; ii) investigate the significant parameters that affect the stream flow simulation.

\section{METHODS}

The area of study is situated in the north part of Morocco and covers an area of about $940 \mathrm{~km}^{2}$ (Fig 1). The Laou Basin extends over two contrasting climatic regions of Morocco, the Mediterranean sub-humid in the mountainous regions and the semi-arid. The Laou Basin dominates the coastal zone. Rainfall in this basin is significant compared to other basins in Morocco, with an annual average of $473 \mathrm{~mm}$ downstream and $1361 \mathrm{~mm}$ upstream. The majority of precipitation (about 65\%) occurs between April and June.

The SWAT model needs several kinds of input information. We compiled these data from a variety of sources, as noted below, and a number of processes were implemented.

\section{SWAT model}

Developed by the United States Department of Agriculture (USDA), the SWAT model allows the climate data to be integrated, hydrological and biological processes as well as complex phenomena such as erosion, infiltration and agricultural practices.[Tuppad et al., 2011][J G Arnold

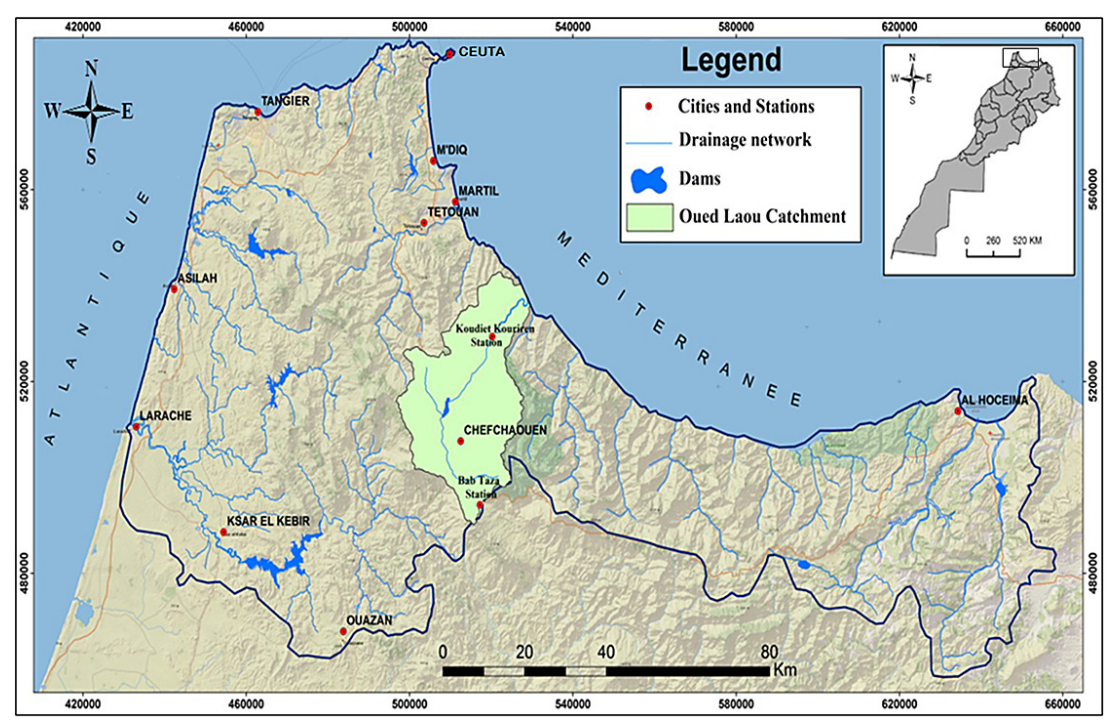

Figure 1. Situation map of the Laou basin 
and Fohrer, 2005][Jeffrey G Arnold, Moriasi, Gassman and White, 2012]. This model functions with thin space-time units. The corresponding time is daily and the resolution is the Hydrological Response Unit. HRUs are geographical units considered homogeneous from a water point of view, pedo-climatic and land use. These HRUs are non-spatialized but are distributed within the sub-basins that are. These sub-basins divide the basin into slope by river segments [Bouraoui, 2005][Hallouz, Meddi, Mahé and Alirahmani, 2017]. It is at the scale of these units that the model calculations are performed. These calculations are based on multiple equations from extensive research [Monteith, s.d.][S.L. Neitsch, J.G. Arnold, J.R. Kiniry, 2009]. Surface runoff is simulated employing the Soil Conservation Service Curve Number (SCS-CN) process. Green \& Ampt infiltration method are used for the infiltration modeling. The surface flow was calculated by a kinematic method and the return flow was predicted assuming a shallow aquifer [Jeffrey G. Arnold a et $\sim$ u.s, 1992][J.R. Williams, 1975] [Overton, 1966].

SWAT, similarly to other hydrological models, reproduces the water cycle in the watershed in a simplified way. The modeling can be divided into two parts:

- A "sub-basin" component that allows water balances to be carried out on each sub-basin, which are then integrated throughout the basin,
- B "transfer" component that transfers water from the networks to the outlet.

The operating principle established by SWAT in this research is represented below:

SWAT necessitates specific information on climate, soil properties, topography, vegetation, and cultural practices for each HRU. There are three steps in the functioning of SWAT:

- The consideration of topography by the DEM (digital elevation map), for this work, a $12.5 \mathrm{~m}$ $\times 12.5 \mathrm{~m}$ resolution DEM was obtained from the Alaska Satellite Facility, which enables to define the hydrographic network. It is possible to choose the outlets to delimit the sub-watersheds.

- Cross-referencing information on land use and soil type. It allows us to define the different HRUs. The more precisely these fields are filled in, the greater the number of HRUs. Then, the model can consider the different evapotranspiration values according to crop type, soil type and crop management. Soilspecific parameters had to be entered manually. SWAT has its own database, but it is specific to the soils of the United States and did not correspond to those of Morocco. It was therefore necessary to collect these data in advance (number of horizons, depth, granulometry, albedo, hydraulic conductivity...) for the two types of soils (Combisol and Arenosol) present in the Laou basin.

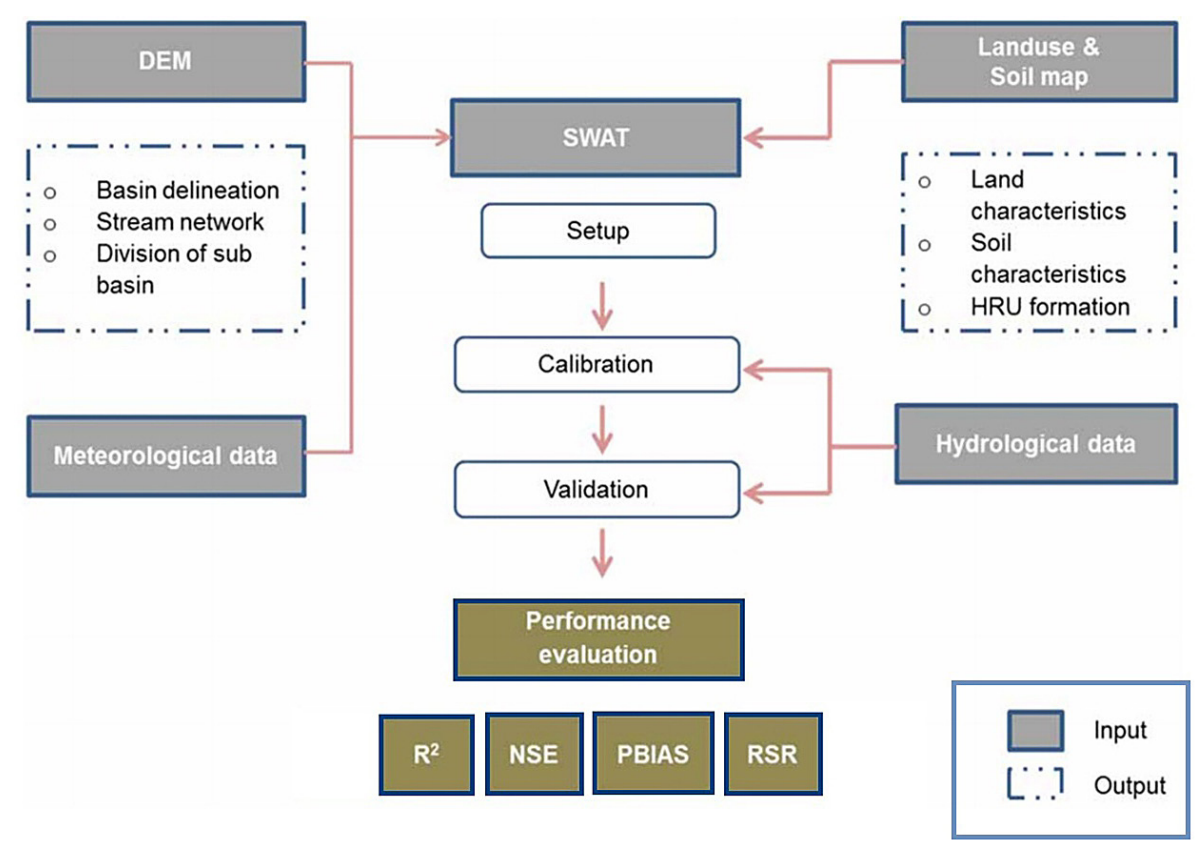

Figure 2. Structure of Methodology of modeling under Arc-SWAT. 
- SWAT already has tables filled in for a large number of crops or other types of land use (forest, urban area, etc.). However, similarly as for soils, these tables are published for the American territory and therefore do not take into account all countries. In our case, the Laou basin parameters, which were integrated into SWAT, were found in the scientific literature, and discussed with the researchers subsequently completed directly in SWAT.

\section{Meteorological Data}

SWAT allows the integration of several weather stations into the modeling. As a first step, the location of these stations (two weather stations were available for simulations (Kodiat Korireen, Bab Taza)), their altitude and the monthly average of each climatic parameter should be entered in the database. In the second step, the daily data of these different parameters can be indicated during the modeling. In the event that certain parameters are missing, or a data gap period appears, SWAT allows carrying out a simulation of these parameters from the station's monthly reference data.

The principal data employed in the study took into account climatic data: daily precipitation and flow data (2014 to 2011) from the watershed agency of Loukkos (ABHL) Tetouan Morocco, temperatures ( $\min , \max$, average daily), relative humidity, wind speed and solar radiation.

\section{Spatial discretization in SWAT}

Spatial discretization is the first step in running the model. It consists in extracting from the
DEM the boundaries of the Laou catchment area and its hydrographic network. In SWAT, the procedure for delimitation is automated. The first thing to do is to indicate the location of the DEM one wants to use for the delimitation. The calculation of the limits is then carried out in five steps:

- Inlay of the real hydrographic network

- Filling of low points and calculation of slopes

- Determination of flow directions

- Calculation of drained surfaces

- Automatic extraction from the hydrographic network

- Determination of the boundaries of the watershed

The treatment of DEM first resulted in the creation of 24 sub-basins. At each stream portion intersection, the model placed a potential outlet, and therefore created a sub-basin.

Once the hydrographic network was determined and the boundaries of the watershed extracted, SWAT proposed to integrate soil, land use and slope class data. As for the soil data, it was sufficient to indicate the location of the previously digitized "soil map" layer (Fig 3), taking care to always present it in the same coordinate system. Afterwards, the software cut the soil layer through the previously established basin boundaries.

It was then necessary to establish the correspondence between the soil types on the map and the previously filled SWAT soil table, where the values of the parameters used by the model (number of horizons, depth, water capacity, granulometry, etc.) were recorded. Land use works in the same way as the soil map. The location of the
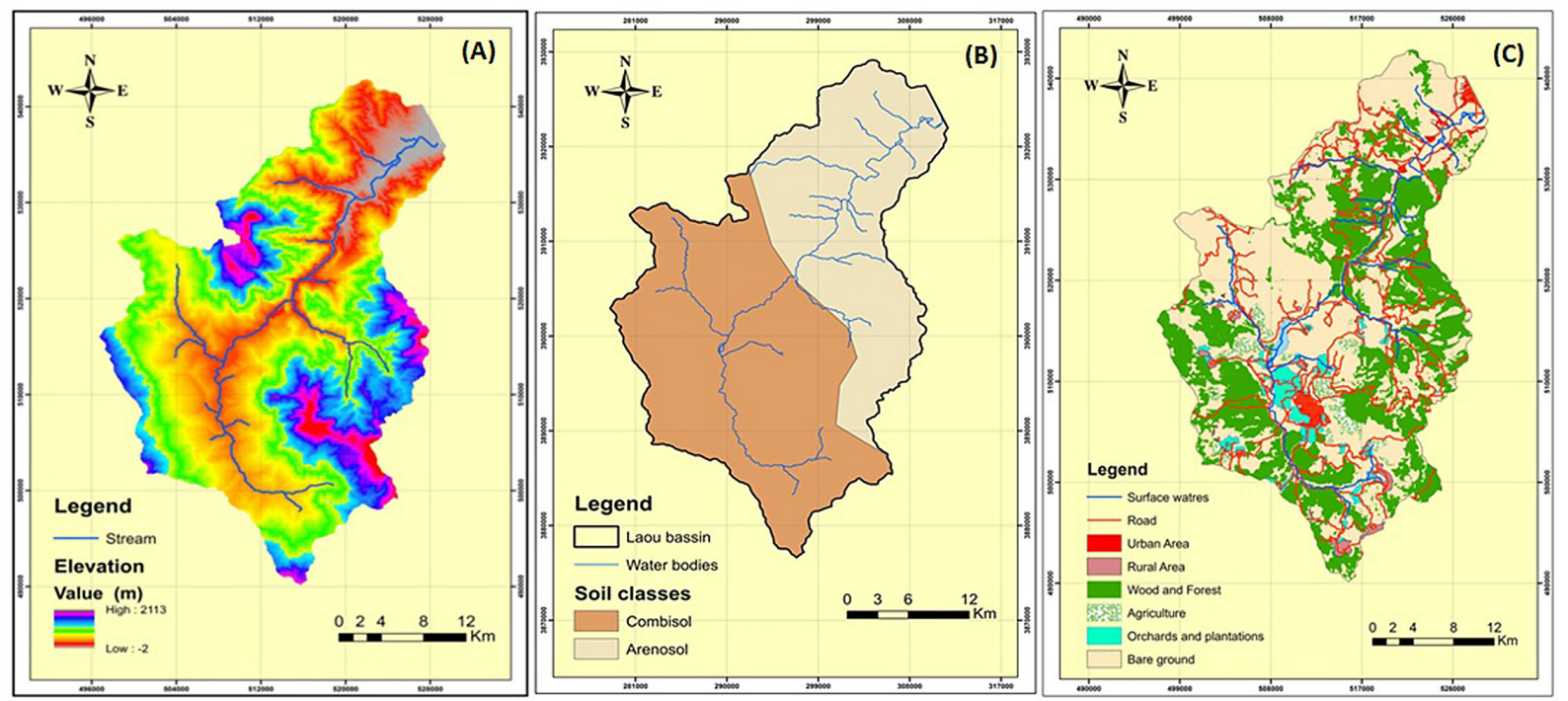

Figure 3. The chosen parameters of this study (A) Elevation, (B) Soil map, (C) Land use 


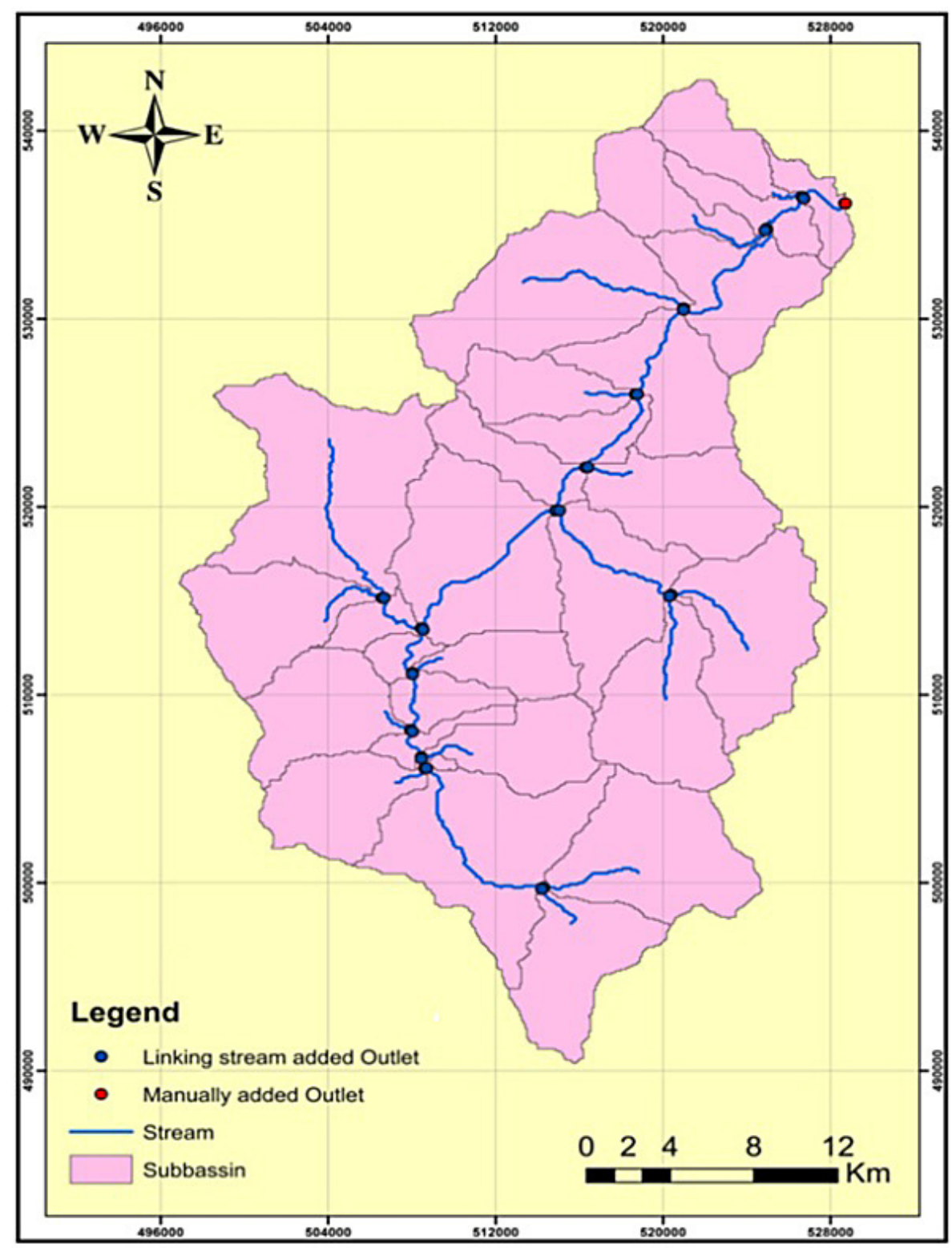

Figure 4. Watershed delineation.

digitized land cover layer (Fig 3) was indicated by mapping the crop types to the SWAT.

In order to take the heterogeneity of the environment into account and to better model the different processes, SWAT spatializes the response types; the model calculates the quantitative value of the different processes on each unit space. The basic unit of calculation is the HRU (Hydrological Response Unit). This discretization in subunits corresponds to the combination, for a subwatershed, a soil type, slope class and land use type the parameters of which influence hydrological processes (runoff, infiltration, evapotranspiration...). A HRU therefore has its own homogeneous hydrological behavior. The water flow is thus calculated on the basis of this unit and then summed to provide an overall value at the outlet of the basin. SWAT's HRU distribution control allows the user to specify certain criteria that influence the distribution mode.

\section{Simulations}

The data was integrated into the model to start the simulation. The first step was to define the time period over which the simulation is to be performed which daily flow measurements in the Laou River from 2004 to 2011. Then we chose the time step for data output, which initially constituted a monthly step. Then, considering that the flow measurements over the basin were 
daily, the simulations were also chosen at the daily time step.

In order to allow a better match between the simulated and observed variables, it was necessary to adapt some model parameters. This phase is called calibration. It focused on the soil parameters that have a critical impact on simulations. The first calibration control variable concerns the flow rate of the measuring station, at the monthly time step, then at a second time at the daily time step.

Three analyses are possible in SWAT; it is possible to test the sensitivity of the variables: flows, sediments and surface water qualities. We chose to focus on the analysis applies to a sub-basin for a given simulation and create an output file where a rank is assigned to each tested parameter. Then, 28 parameters that can be applied for calibration, all 28 flows related parameters changed and tested, as results six parameters were obtained after 250 runs. The results are as follows (Table 1):

The surface runoff from daily precipitation was assessed by the modified SCS-CN method [Savvidou, Efstratiadis, Koussis, Koukouvinos et Skarlatos, 2018]. In this approach, the amount of runoff was estimated based on local land use, soil type and historical soil moisture.

\section{Model performance evaluation}

Several studies recommended four statistics coefficient to test the model performance; The Nash-Sutcliffe efficiency (NSE), percent bias (PBIAS), coefficient of determination $\left(\mathrm{R}^{2}\right)$, and the square error (RSR) [D. Moriasi, Arnold and Liew, 2013][Pachepsky, Martinez, Pan, Wagener and Nicholson, 2016][Golmohammadi,
Prasher, Madani and Rudra, 2014b]. The performance criteria used for flow simulation are presented in Table 2.

The Nash-Sutcliffe coefficient (NSE) [Nash and Sutcliffe, 1970] calculated as:

$$
N a s h=1-\left\lfloor\frac{\sum_{i=1}^{n}\left(Y_{i}^{\text {obs }}-Y_{i}^{\text {sim }}\right)^{2}}{\sum_{i=1}^{n}\left(Y^{\text {obs }}-Y^{\text {mean }}\right)^{2}}\right\rfloor
$$

The PBIAS percentage (PBIAS) [Franz and Hogue, 2011] which is calculated as:

$$
P B I A S=\left[\frac{\sum_{i=1}^{n}\left(O_{i}-P_{i}\right) * 100}{\sum_{n=1}^{n}\left(O_{i}\right)}\right]
$$

The model performance RSR [Shcherbakov and Brebels, 2013] which is calculated as:

$$
R S R=\frac{R M S E}{S T D E V_{O b s}}=\left[\frac{\sum_{i=1}^{n}\left(o_{i}-P_{i}\right)^{2}}{\sqrt{\sum_{i=1}^{n}\left(o_{i}-O\right)^{2}}}\right]
$$

The coefficient of determination $\mathrm{R}^{2}$ [Garba and Chukwujama, 2016] equation is:

$$
\mathrm{R}^{2}=\left[\frac{\sum\left(Q_{o b s}-Q_{o b s}\right)^{2}-\sum\left(Q_{\text {sim }}-Q_{\text {sim }}\right)^{2}}{\sum\left(Q_{o b s}-Q_{o b s}\right)^{2}}\right]
$$

\section{RESULTS AND DISCUSSION}

The model was first calibrated and validated against flow measurements in order to best represent the cycle of water. The SWAT was run for daily stream flow in Laou River from 2004 to 2011. The calibration for 2004-2008 and the validation of flows on 2008-2011 gave satisfactory results, in particular regarding the difference between the observed and simulated totals remains small (close to $10 \%$ over the two simulations

Table 1. The six most sensitive SWAT parameters used in the Laou watershed

\begin{tabular}{|c|l|l|c|}
\hline Rank & \multicolumn{1}{|c|}{ SWAT Parameters } & \multicolumn{1}{c|}{ Description } & Initial range value \\
\hline 1 & CN2 (dimensionless) & Curve Number, moisture condition II & $(69.8-93.0)$ \\
\hline 2 & ESCO (dimensionless) & Soil evaporation compensation factor & $(0.01-1.0)$ \\
\hline 3 & SOL_AWC $(\mathrm{mm} / \mathrm{mm})$ & Available soil moisture capacity, $\mathrm{mm} \mathrm{h} \mathrm{-1}$ & $(-0.6$ to 0.6$)$ \\
\hline 4 & ALPHA_BF $(1 /$ day $)$ & Base Flow recession constant, days & $(0-0.048)$ \\
\hline 5 & CH_N2 $(\mathrm{s} / \mathrm{m} 1 / 3)$ & Manning's "n" value for the main channel & $(0.01-0.25)$ \\
\hline 6 & CH_k2 $(\mathrm{mm} / \mathrm{h})$ & Effective hydraulic conductivity in the channel alluvium & $(0-150)$ \\
\hline
\end{tabular}

Table 2. Performance measurements for stream flow simulation [D. N. Moriasi, Gitau, Pai and Daggupati, 2015].

\begin{tabular}{|l|c|c|c|c|}
\hline \multicolumn{1}{|c|}{ Performance rating } & NSE & RSR & PBIAS & $R^{2}$ \\
\hline Unsatisfactory & NSE $\leq 0.5$ & RSR $>0.7$ & PBIAS $\geq \pm 25$ & $R^{2}<0.50$ \\
\hline Satisfactory & $0.5<$ NSE $\leq 0.65$ & $0.6<\mathrm{RSR} \leq 0.7$ & $\pm 15 \leq \mathrm{PBI} \mid \mathrm{AS}< \pm 25$ & $0.50<\mathrm{R}^{2}<0.70$ \\
\hline Good & $0.65<\mathrm{NSE} \leq 0.75$ & $0.5<\mathrm{NSE} \leq 0.6$ & $\pm 10 \leq \mathrm{PBI} \mathrm{AS}< \pm 15$ & $0.70<\mathrm{R}^{2}<0.80$ \\
\hline Very good & $0.75<\mathrm{NSE} \leq 1$ & $0.5<\mathrm{NSE} \leq 0$ & $\mathrm{PBI}$ IAS $< \pm 10$ & $>0.80$ \\
\hline
\end{tabular}


periods); this criterion of the quality of the simulations is important.

The model estimates the stream flow by using 28 SWAT significant parameters, but in Laou basin it found that the most prominent parameters were: 1) the initial SCS runoff curve number for moisture condition II (CN2); although SWAT is a physically based model, some phenomena are represented by empirical functions, such as, for example, runoff, for that reason $\mathrm{CN}$ was fairly important during the modeling. 2) ESCO soil evaporation compensation factor, this parameter enables to vary the quantity of water that can be extracted from the ground to meet the evaporative demand and it was increased during calibration period. 3) SOL_AWC value was greatly increased during calibration, just as reported by [Fadil, Rhinane, Kaoukaya, Kharchaf and Bachir, 2011] 4) The value of ALPH_BF has a highest value, but it gives a reasonable value for NSE. 5) The $\mathrm{CH}_{-} \mathrm{N} 2$ seems reasonable. 6) The $\mathrm{CH}$ _K2 parameter influences the exchanges between the river and the groundwater and therefore makes the watercourse less impermeable, which buffers the signal; not only in our study, but also in many other studies that have the same initial conditions as Laou basin in different basins around the world
[Čerkasova, 2018][Perez-valdivia, Cade-menun and Mcmartin, 2017][Yu et al., 2018].

The six parameters identified among the others (28) during the sensitivity analysis were determined as the most important for the SWAT calibration phase; we found that despite persisting in setting the other parameters, the results remain the same. Therefore, these parameters have no effect on the flow simulation in the Laou basin, during manual calibration process the same result was obtained by [Khalid, 2018].

Finally, the calibration of hydrology ends with the adjustment of surface flows. These are influenced by other parameters previously used to calibrate the daily flows in the Oued Laou basin. Therefore, it is possible to refine them but this does not change the model's performance much.

It was found that the parameters relevant to topographical variation and Land use had higher sensitivity during model calibration for the Laou watershed moreover parameters related to soil and groundwater were more sensitive for modeling this basin. The analysis of these different physical and geomorphological (lithological) parameters allows a better understanding of the causes of variations in the hydrological regimes of the studied watershed area and consequently

Table 3. Ratings of the recommended parameters for stream flow simulation.

\begin{tabular}{|l|c|c|c|c|}
\hline \multicolumn{1}{|c|}{ Parameters } & Minimum calibration value & Maximum calibration value & Initial value & Calibrated Value \\
\hline CN2 (dimensionless) & 20 & 90 & $(69.8-93.0)$ & 74 \\
\hline ESCO (dimensionless) & 0.03 & 1 & $(0.01-1)$ & 0.83 \\
\hline SOL_AWC $(\mathrm{mm} / \mathrm{mm})$ & -0.6 & 0.6 & $(-0.6$ to 0.6$)$ & 0.4 \\
\hline ALPHA_BF $(1 /$ day) & 0 & 0.048 & $(0-0.048)$ & 0.43 \\
\hline CH_N2 $(\mathrm{s} / \mathrm{m} 1 / 3)$ & 0.01 & 0.25 & $(0.01-0.25)$ & 0.15 \\
\hline CH_k2 $(\mathrm{mm} / \mathrm{h})$ & 0 & 150 & $(0-150)$ & 58 \\
\hline
\end{tabular}

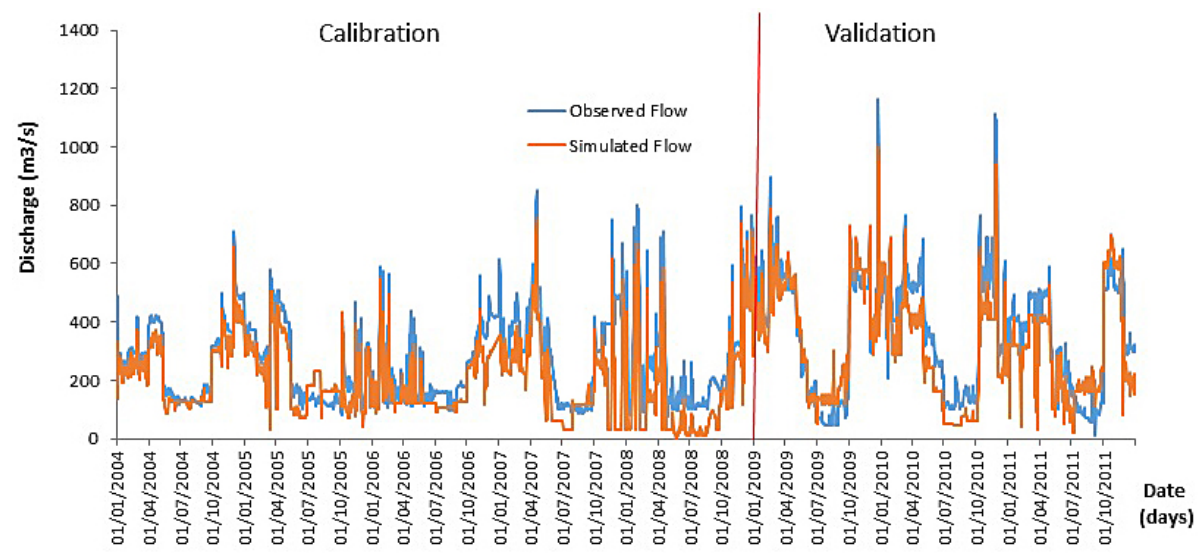

Figure 5. Monitoring and simulating of daily flow in the Laou river during the calibration and validation of the SWAT model. 
their contribution to the genesis of floods. Their interaction determines the variability of hydrological phenomena in time and space.

The model was calibrated and confirmed by comparing the flow rates simulated and monitored at the exit of the basin for the periods 2004-2008 and 2009-2011, respectively. In general, the model shows a favorable concordance of the simulated and the monitored stream flow for the entire Laou basin (Fig 5).

SWAT model shows the highest underestimation in the calibration phase. Over the validation period, the model worked more efficiently compared to the calibration period. All statistical values were in the "very good" and "good" ratings. According to the relevant indicators, the assessment indicates that the SWAT model was well performing for the calibration and validation phases in the Laou watershed. Indeed, the model demonstrated a strong correlation for the observed and simulated daily average flow of the river with $\mathrm{R}^{2}$ and a Nash coefficient about (0.8). The components of the water balance were correctly estimated, in other respect PBIAS improved in calibration and in the validation period, falling into the 'very good' range, indicating good water balance agreement with the SWAT simulations. The RSR results were reported as 0.52 and 0.41 for the two phases of the simulation process, respectively.

Table 4. Goodness-of-fit statistics for general daily discharge modeled by the SWAT model in the Laou River.

\begin{tabular}{|c|c|c|c|c|}
\hline $\begin{array}{c}\text { Performance } \\
\text { rating }\end{array}$ & NSE & RSR & PBIAS & $\mathrm{R}^{2}$ \\
\hline $\begin{array}{c}\text { Calibration } \\
(2004-2008)\end{array}$ & 0.76 & 0.52 & 12.24 & 0.74 \\
\hline $\begin{array}{c}\text { Validation } \\
(2009-2011)\end{array}$ & 0.84 & 0.41 & 8.93 & 0.82 \\
\hline
\end{tabular}

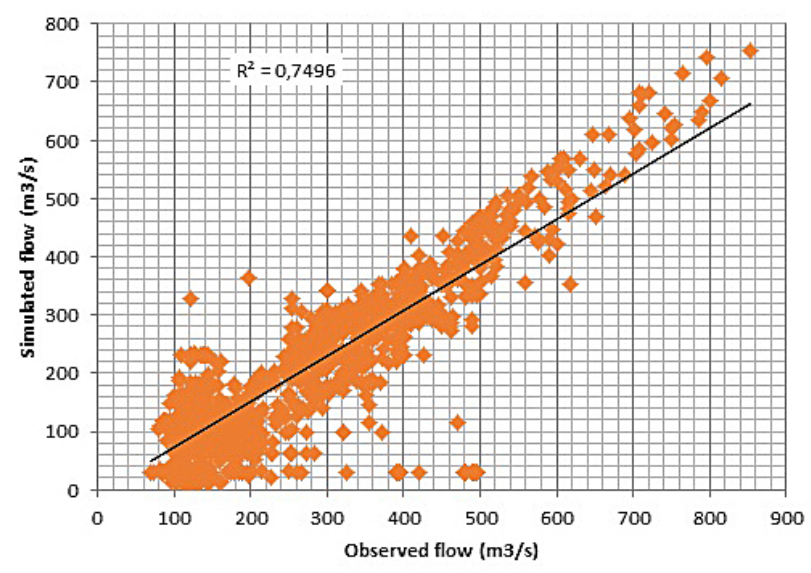

This shows high performance values throughout the modeling years as well. The selected model was validated on a temporal scale for the entire measurement period in the Laou watershed.

These results revealed that SWAT was adapted to the two climate regions of Laou watershed, and affirmed the flexibility of SWAT model. The proposed methodological approach enabled to synthesize the hydrological functioning of the watershed analyzed and to test the performance of the SWAT model, as well as to study the significant parameters affecting the simulation of the flows of the Laou basin. The application and testing of SWAT model in hydrology remains a major challenge for very active research field compared to conventional models, because it involves the parameters that assist in knowing the hydrological functioning; therefore, it is essential to study and obtain reliable data of these parameters.

\section{CONCLUSION}

This study was carried out in northern Morocco for the modeling of daily flows with the SWAT model. The findings indicate that SWAT is a suitable approach for modeling hydrological responses in the Laou geographical region and in this type of climatological context. The model was subsequently tested on a daily basis through manual calibration with the aid of historical flow records of the Laou river. The model was satisfactorily adjusted compared to the observed flow. The identified parameters of SWAT were $(\mathrm{CN} 2$, ESCO, SOL_AWC, ALPHA_BF, CH_N2 and $\mathrm{CH}_{-} \mathrm{k} 2$ ) it was found that the parameters relevant to the topographical variation and Land use had higher sensitivity during the model calibration.

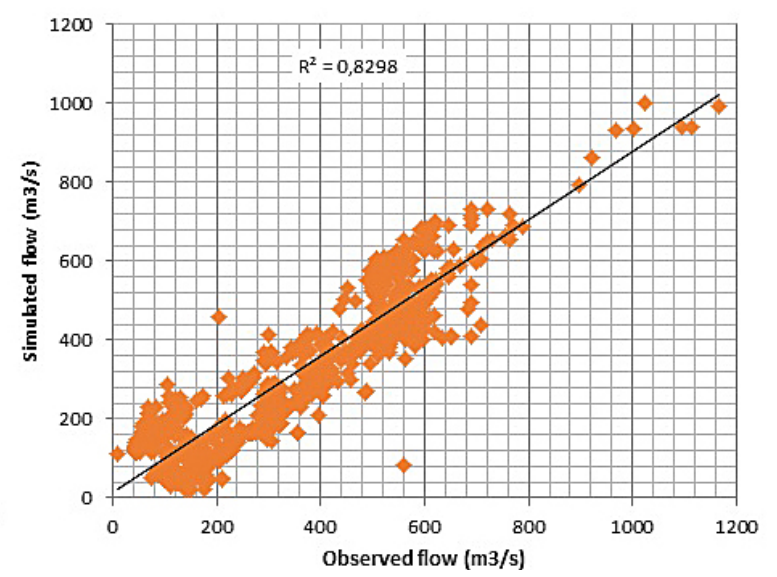

Figure. 6 Scatter plot of daily stream flow for calibration and validation period 
Moreover, the parameters related to soil and groundwater were more sensitive for modeling in our watershed study. This study showed the feasibility of implementing the SWAT model because it enabled to simplify the representation of the flows on the Laou watershed estuary, especially in this climatic zone. Furthermore, these results reinforced the multi-functionality and reliability of SWAT as a hydrological model and a relevant tool for water resources management and controls.

\section{Acknowledgements}

Special thanks to the Watershed Agency of Loukkos of Tetouan, Morocco for supporting this research by providing basic data.

\section{REFERENCES}

1. Ang, R. et Oeurng, C. 2017. Simulating stream fl ow in an ungauged catchment of Tonlesap Lake Basin in Cambodia using Soil and Water Assessment Tool ( SWAT ) model. TITLE=Water Science. doi:10.1016/j.wsj.2017.12.002

2. Aqnouy, M., Eddine, J., El, S., Bouadila, A., Bouizrou, I. et Aoulad, M. R. 2018. Application of hydrological model « HEC HMS » In a Mediterranean watershed ( Oued Laou, Northern of Morocco ), 24(4), 1773-1781.

3. Arnold, J. G. et Fohrer, N. 2005. SWAT2000 : current capabilities and research. hydrological processes, 572, 563-572. doi:10.1002/hyp.5611

4. Arnold, J. G., Moriasi, D. N., Gassman, P. W. et White, M. J. 2012. SWAT : Model use, calibration, and validation.

5. Borah, D. K. et Bera, M. 2003. watershed-scale hydrologic and nonpoint-source pollution models: review of mathematical bases. transactions of the asae, 46(6), 1553-1566.

6. Bouraoui, F. (2005). Application of the SWAT model on the Medjerda river basin ( Tunisia ), 30, 497-507. doi:10.1016/j.pce.2005.07.004

7. Čerkasova, N. 2018. Development of a hydrology and water quality model for a large transboundary river watershed to investigate the impacts of climate change - A SWAT application. Ecological Engineering, 124(September), 99-115. doi:10.1016/j. ecoleng.2018.09.025

8. Costa, D., Avelino, R., Sára, S., Thomazini, L., Aurélio, M. et Caiado, C. 2015. Application of the SWAT hydrologic model to a tropical watershed at Brazil. Catena, 125, 206-213. doi:10.1016/j.catena.2014.10.032
9. Fadil, A., Rhinane, H., Kaoukaya, A., Kharchaf, Y. et Bachir, O. A. 2011. Hydrologic Modeling of the Bouregreg Watershed (Morocco) Using GIS and SWAT Model. Journal of Geographic Information System, 3(4), 279-289. doi:10.4236/ jgis.2011.34024

10. Franz, K. J. et Hogue, T. S. 2011. Evaluating uncertainty estimates in hydrologic models: borrowing measures from the forecast verification community, (1884), 3367-3382. doi:10.5194/hess15-3367-2011

11. Garba, H. et Chukwujama, I. A. 2016. Evaluating the performance of a hydrological model on River Kaduna discharge, 6(1), 25-29.

12. Golmohammadi, G., Prasher, S., Madani, A. et Rudra, R. 2014a. Evaluating Three Hydrological Distributed Watershed Models: MIKE-SHE, APEX, SWAT, 20-39. doi:10.3390/hydrology1010020

13. Golmohammadi, G., Prasher, S., Madani, A. et Rudra, R. 2014b. Evaluating Three Hydrological Distributed Watershed Models: MIKE-SHE, APEX, SWAT, (August 2016). doi:10.3390/hydrology 1010020

14. Haberlandt, U. 2010. Advances in Geosciences From hydrological modelling to decision support, 11-19. doi:10.5194/adgeo-27-11-2010

15. Hallouz, F., Meddi, M., Mahé, G. et Alirahmani, S. 2017. Modeling of discharge and sediment transport through the SWAT model in the basin of Harraza ( Northwest of Algeria ). TITLE=Water Science. doi:10.1016/j.wsj.2017.12.004

16. Halwatura, D. et Najim, M. M. M. 2013. Application of the HEC-HMS model for runoff simulation in a tropical catchment. Environmental Modelling and Software, 46, 155-162. doi:10.1016/j.envsoft.2013.03.006

17. Haron, S. H., Khalid, K., Ali, M. F., Faiza, N. et Rahman, A. 2016. Application of the SWAT Hydrologic Model in Malaysia : Recent Research Application of the SWAT Hydrologic Model in Malaysia :, (March).

18. J.R. Williams. 1975. Hymo flood routing*. Journal of Hydrology,26 (1975) 17-27, 26, 17-27.

19. Jeffrey G. Arnold a, P. M. A. b and G. B. c et $\sim$ u.s. (1992). A comprehensive surface-groundwater flow model. Journal of Hydrologic, 142 (1993) 47-69, 142, 47-69.

20. Jha, M. K. 2011. Evaluating Hydrologic Response of an Agricultural Watershed for Watershed Analysis, 604-617. doi:10.3390/w3020604

21. Khalid, C. 2018. Hydrological modeling of the Mikkés watershed (Morocco) using ARCSWAT model. Sustainable Water Resources Management, 4(1), 105-115. doi:10.1007/s40899-017-0145-0

22. Khatun, S. 2018. Simulation of surface runoff 
using semi distributed hydrological model for a Simulation of surface runoff using semi distributed hydrological model for a part of Satluj Basin : parameterization and global sensitivity analysis using SWAT CUP. Modeling Earth Systems and Environment, 0(0), 0. doi:10.1007/s40808-018-0474-5

23. Leach, J. M., Kornelsen, K. C. et Coulibaly, P. 2018. Assimilation of near-real time data products into models of an urban basin. Journal of Hydrology, 563(May), 51-64. doi:10.1016/j.jhydrol.2018.05.064

24. Monteith, J. (s.d.). Evaporation and environment.

25. Moriasi, D., Arnold, J. et Liew, M. W. Van. 2013. Model Evaluation Guidelines for Systematic Quantification of Accuracy in Watershed Simulations, (May 2007). doi:10.13031/2013.23153

26. Moriasi, D. N., Gitau, M. W., Pai, N. et Daggupati, P. (2015). Hydrologic and Water Quality Models: Performance Measures and Evaluation Criteria. Transactions of the ASABE, 58(6), 1763-1785. doi: $10.13031 /$ trans.58.10715

27. Nash, J. E. et Sutcliffe, J. V. 1970. River Flow Forecasting Through Conceptual Models Part I-a Discussion of Principles*. Journal of Hydrology, 10, 282-290. doi:10.1016/0022-1694(70)90255-6

28. Overton, D. E. 1966. MUSKINGUM study. K is referred to as reach travel time, and $\mathrm{X}$ is a coefficient used to weigh the relative effects of inflow and outflow on reach storage. The effectiveness of the routing system depends on factual estimates of the coefficients. An atte. Journal of Hydrology, 4.

29. Pachepsky, Y. A., Martinez, G., Pan, F., Wagener, T. et Nicholson, T. 2016. Evaluating Hydrological Model Performance using Information Theorybased Metrics, (February), 1-24. doi:10.5194/hess2016-46

30. Panhalkar, S. S. 2014. Hydrological modeling using SWAT model and geoinformatic techniques. the egyptian journal of remote sensing and space. doi:10.1016/j.ejrs.2014.03.001

31. Perez-valdivia, C., Cade-menun, B. et Mcmartin, D. W. 2017. Journal of Hydrology : Regional Studies Hydrological modeling of the pipestone creek watershed using the Soil Water Assessment Tool ( SWAT ): Assessing impacts of wetland drainage on hydrology. Journal of Hydrology: Regional Studies, 14(June), 109-129. doi:10.1016/j. ejrh.2017.10.004

32. Polanco, E. I., Fleifle, A., Ludwig, R. et Disse, M. 2017. Improving SWAT model performance in the upper Blue Nile Basin using meteorological data integration and subcatchment discretization, 4907-4926.

33. Quan, Z., Teng, J., Sun, W., Cheng, T. et Zhang, J. 2015. Evaluation of the HYMOD model for rainfall-runoff simulation using the GLUE method. IAHS-AISH Proceedings and Reports, 368(August 2014), 180-185. doi:10.5194/piahs-368-180-2015

34. S.L. Neitsch, J.G. Arnold, J.R. Kiniry, J. R. W. 2009. Soil \& Water Assessment Tool Theoretical Documentation Version 2009. Texas Water Resources Institute Technical Report No. 406 Texas A\&M University System, College St.

35. Savvidou, E., Efstratiadis, A., Koussis, A. D., Koukouvinos, A. et Skarlatos, D. 2018. The curve number concept as a driver for delineating Hydrological Response Units. Water (Switzerland), 10(2). doi:10.3390/w10020194

36. Shcherbakov, M. V. et Brebels, A. 2013. A Survey of Forecast Error Measures, 24(4), 171-176. doi:10.5829/idosi.wasj.2013.24.itmies.80032

37. Sith, R. et Nadaoka, K. 2017. Comparison of SWAT and GSSHA for High Time Resolution Prediction of Stream Flow and Sediment Concentration in a Small Agricultural Watershed. Hydrology, 4(2), 27. doi:10.3390/hydrology4020027

38. Skahill, B. E. 2004. Use of the Hydrological Simulation Program - FORTRAN ( HSPF ) Model for Watershed Studies. System-wide Modeling, Assessment, (September).

39. Tuppad, P., Mankin, K. R. D., Lee, T., Srinivasan, R. et Arnold, J. G. 2011. soil and water assessment tool (swat) hydrologic/water quality model: extended capability and wider adoption. American Society of Agricultural and Biological Engineers ISSN 2151-0032, 54(2007), 1677-1684. 